\title{
Impact of Han Cultural Thinking Orientation on Ideographic Characteristics of Chinese Painting
}

\author{
S.S. TAO \\ School of Arts, Huangshan University, Huangshan, China
}

\begin{abstract}
As two important painting styles alternatively derived from the Han cultural thinking, the realistic and ideographic characteristics of Chinese painting faced different perspectives of different mainstream thinking orientations of the observers. The evolution of the cultural life naturally affected the changes of the painting style. In this article, the origin, crisis and the artistic conception of "rhythmic vitality" of the painting's ideographic characteristics were revealed through studies on long painting history from the Former Qin Dynasty up to now. Additionally, the unique understanding on the restoration of the painting's ideographic characteristics to be the mainstream of Chinese paintings was discussed through presenting the issues shown at the intrinsical level of paintings.
\end{abstract}

KEYWORD: Ideographic characteristics; Chinese painting; The Han culture; Thinking orientation; Philosophical consciousness

\section{THE CULTURAL CHARACTERISTICS OF THE HAN NATIONALITY AND EARLY REALISTIC PAINTINGS}

From the beginning of development, Chinese paintings had been marked with the labels of the Chinese thinking and the philosophical consciousness, using Figure 1 as an example. The rough grasp of appearances and straight life attitude were not only the life attitude of the society but also the realm of the aesthetic pursuit, which gradually developed into the main characteristics of the Chinese painting style.

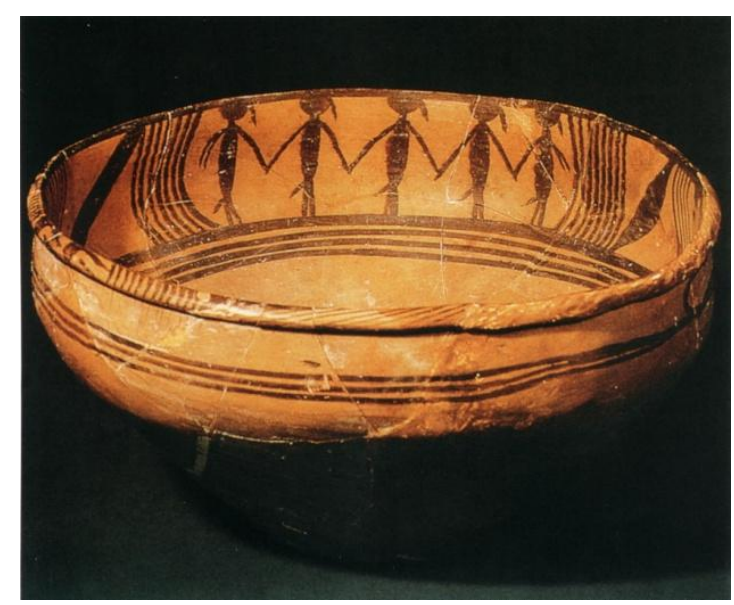

Figure 1. A basin with dancing figures (B.C. 3300-B.C. 2025), excavated in Majiayao
As recorded in the art history of other nationalities, people always experienced the course of simulating objective reality at the early stage of artistic development and so it was for the art in the Former Qin Dynasty. However, at the beginning of the artistic work, the imagery aesthetic characteristics of the Han nationality were shown at the same time of real world simulation (Sheng J.H. 2014). Although few paintings of the Former Qin Dynasty had been seen, but viewed from the historical data, the rationality under the governance of the legalists and the practical social philosophy during the Qin Dynasty inevitably affected the artistic creation. Only under a situation with open and free social morality, could the culture have the opportunity to show itself and the possibility to reflect the style and aesthetic appreciation of an era. And there is no doubt that the artists can have ambitions under such circumstance. Archeological materials have provided us with vivid and realistic sculptures, paintings and excavated works (such as the terra-cotta warriors of the Qin Imperial Mausoleum) of the Qin and Han Dynasty. The painting style of the Qin Dynasty reflected the actual basic thinking that the nationality was pursuing reality. And the remains of ancient Qin Dynasty seen nowadays were works created for practical use and their using function determined their styles and forms. However, located at a northwest corner of China, the Qin Dynasty only ruled China for twenty 
years. The short duration of unity didn't sufficiently manifest the Chinese culture, especially its potential various genres. The terra-cotta warriors, chariots and sculptures which are included in artworks currently were very practical implements at that time. With strict political and social objective requirements, they often reflected the national interest of the northwest region in those days. It was not until the Han Dynasty did the Chinese culture turn out to be the subject of the Han culture (i.e. Chinese culture) over hundreds of years' development and did the styles of artistic creation carry on the styles of the Former Qin Dynasty. From then on, the characteristics of the Han nationality became to be the main characteristics of the Chinese nation.

\section{CRISIS BROUGHT BY WESTERN IDEOLOGY ON THE IDEOGRAPHIC CHARACTERISTICS OF PAINTING}

The system of Chinese painting had established the general theoretical characteristics from the "six legal codes" theory of Xie He. The Han Dynasty and the following hundreds of years before the Six Dynasties were the formative period of Chinese painting style. The ideographic characteristics, color applying methods and using of mineral pigment of the paintings on silk excavated from Mawangdui in Hunan Province can be easily understood, which embodied exactly the same painting characteristics as that of the painting of the Han Dynasty. The abovementioned fact indicates that the style of Chinese painting became mature gradually in the course of ethnic fusion. And the landscape painting entered a peak time of maturity during the period of Ming and Qing Dynasty, which reflected the demand of rhythmic vitality of the humanistic spirit. From then on, the painting returned to the original point from the starting point of the "six legal codes" theory. Under the military and economic impact of the western industrial society, the traditional painting and Chinese society had the style and form of the culture and painting as well as aesthetic appreciation changed towards the west. The ideographic painting characteristics had once lost the dominant position in the mainstream painting exhibition, which indicated the decline of the traditional Chinese painting and led to the theory of "the Fade of Traditional Landscape Painting".

Nurtured by Chinese culture, traditional Chinese painting will not disappear although the painting techniques may fade out of history. Chinese painting, regardless of the forms in which they are presented, will preserve, as long as the culture lasts. To develop Chinese culture in a healthy way, the basis of the philosophy and social ideology of China shall not be lost. Facing a severe situation of cultural recession with English to be the common language of the internet, the intensifying of the English language brought by the examination system over decades, and the servility and worship of foreign things of the national formed under the strong western military and economic pressure since the Opium War, the contemporary culture had the main characteristics with the outstanding national culture fading and with the traditional Chinese culture being eroded by the imported culture and dominant ideology which incorporate English. In aesthetic appreciation, people always judge China from a western point of view in both elementary and higher education and they seemed to be more familiar with all the western painting styles and main painters than that of China in either the professional competition or the people's life. In other words, the western aesthetic views had been rooted in the educational culture and public awareness of China.

\section{THE CALLIGRAPHIC PAINTING OF THE SCHOLAR-OFFICIALS WERE THE ORIGIN OF THE IDEOGRAPHIC PAINTINGS}

As most of the traditional Chinese literati painters were amateur painters who became officials through the imperial examination, painting was a kind of their entertainment after work or a way to eliminate their tangled emotions in the official circles. So painting was a label of the refined scholars' interests paraded by the mainstream culture, using Figure 2 as an example.

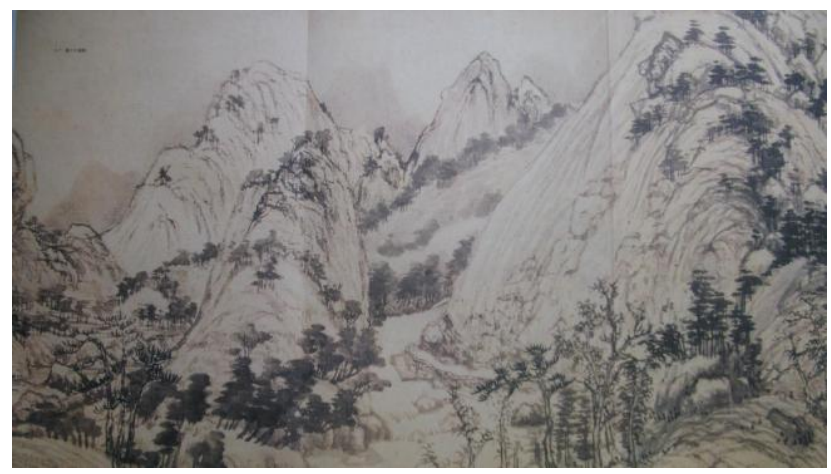

Figure 2. Huang Gongwang Part of the Dwelling in the Fuchun Mountains (1350) Taipei Palace Museum

The picture creation and pursuit of interestingness of works done by Chinese literati painters was necessarily associated with the painter's accomplishment and expressive ability. As started out from the writing in examinations, these literati had proficient calligraphic techniques of using the writing brush and high level of aesthetic appreciation on the calligraphy as good as that of the professional painters. However, since they had insufficient painting skills which restricted their selection of the painting style, they had to pursue the calligraphic and ideographic characteristics in the painting style. 
The "calligraphy and painting homology" means the free calligraphic interestingness expressed by the ideographic characteristics of the painting. The expression of paintings artistically depicted to be "both real and unreal" enabled the literati painters (which were scholar-officials) to express the "spirit beyond the mundane" with their calligraphic ability, leaving aside the technical restriction of the threedimensional spatial expression of the professional painters. The way of giving full play to the technical advantages of the calligraphic ink through "classifying the Chinese ink into five levels", which replaced the objective color expression of "applying colors according to categories", to pursue the general expression of the black-and-white duality-world of Taoism had greatly enable the literati painters to present their speculative philosophy and to occupy a theoretical altitude. The paintings of the literati were common in the cultural circles and had become into a part of the literati's life. And they also represented the elegant taste of the refined scholars. In this way, the paintings of the literati had a strong influence and controlled, and finally, turned out to be the main style of Chinese painting.

The freely painted works of the literati, to some extent, showed that the Chinese people were pursuing an elegant free and easy realm of life. Moreover, it advocated the literati's personalities, i.e. showing up their own characters and interests at the same time of meeting the social law of the middle ground attitude toward the society.

\section{THE INTERACTION BETWEEN PURSUING THE IDEAL OF "UNITY OF MAN AND NATURE" AND THE RHYTHMIC VITALITY OF THE PAINTINGS' IDEOGRAPHIC CHARACTERISTICS}

A general item of "Unity of Man and Nature" was used in the study of Chinese philosophy on the relationship between the human and nature, which expressed the thoughts about the human and the nature, and the ultimate meaning of living in the natural world and the way of getting along with the nature. A high level of achievement was made by the Taoism regarding to this aspect and the Taoism ultimately affected the Chinese people's way of thinking. The observation on the calm and eternity of the nature made them to be the example of ideal pursuit and to be the ideal realm of the life. The images embodied in paintings expressed an ideal kingdom which follows the nature as its law. In the literati's paintings represented by landscape paintings, what people pursued was the easy, peaceful and eternal ideal realm in the nature (landscapes).

The free and careless life style, often expressed by untrammeled images of growing and stretching vegetation, was always desired and pursued by the ancient Chinese literati and scholars. The realm that could be created by the painter's selection of natural landscape description was a world of free and easy life destination. The painter's creation and selection of the mountain and vegetation embodied the righteousness and propriety of the spirit of life (Pan, W.G., Lu, K. and Zhai R. 2013). Therefore, the objects which are often regarded as metaphor of people, such as pines, cypresses, a unique orchid or the plum in the snow, became the painter's first choices in the landscape paintings with ideographic characteristics. The paintings were the specific landscape artistic conception of ideals created by the painter rather than the restatement of any objective real sight, which embodied the spiritual philosophical thinking on the content of the paintings and showed the painter's pursuit in life or the fact that the painter was following the mainstream of the society and culture.

The pursuit and expression of ideal picturesque scene did not always reflect the actual personality of the painter. For example, Qin Hui of the Song Dynasty did excellently in calligraphy, but he acted badly when facing overall national interest and his behavior was regarded as the typical case of persecuting the faithful and upright ones in Chinese culture. Actually, there were many similar cases in Chinese history, such as the eunuch Wei Zhongxian of the Ming Dynasty and the traitor to China-- Wang Ching-wei of the Republic of China. The artistic pursuit of Chinese calligraphy (or the pursuit for ideal personality) was consistent with the painting, both of which was the literati's expression of their personal ideal feelings but were restricted by social factor such as changes of the current politics. For this reason, the paintings and calligraphy works reflected the intellectual's dreams of life in their ideal world. Since the cursive script appeared in the Han Dynasty, the successive generations of calligraphers endeavored to show their styles with the same series of Chinese characters and their works were visual revelations of their feelings during writing.

As the cursive script was the easiest to demonstrate the calligrapher's tastes and interests, compared with other styles of calligraphy, the cursive script had developed gradually closer to aesthetics and was further from reading. The painterly or abstract painting style the writer mentioned hereon is not denying the aesthetic nature of the calligraphies (such as the running script, regular script, official script and seal script) and the ideography of the personality, but emphasizing that the cursive script can reflect the calligrapher's feelings and the emotional interaction with the reader more significantly that other calligraphies.

The narrative styles such as poetries of the Han Dynasty, the Tang poetry and the Song Lyrics had 
played an important role in the expression of the traditional ideology and culture. The painting \& calligraphy and the poetry were different in approach but equally satisfactory in result, they took the same mission with that of the literature and developed a mature form regarding the ideographic characteristics. Emphasizing on the description of the realm, the ideographic literary works was related to the oriental thinking of the Chinese people. This kind of "both real and unreal" metaphor using the theory of "Governing a large country is like frying a small fish." kept the similarity of the whole objective thing and its local and carried the infinite imagination of the Chinese people over thousands of years. There were many examples: "After fresh rain in mountains bare, autumn permeates evening air."(Wang Wei, Autumn Evening in the Mountains); "Without flute songs we drank cur cups with heavy hearts, the moonbeams blent with water when we were to part." (Bai Juyi, Song of a Pipa Player); "Silent, I go up to the west tower alone, and see the hooklike moon. The plane trees lonesome and drear, lock in the courtyard autumn clear. Cut, it won't break, ruled, it will make. A mess to weak, an unspeakable taste in the heart, such is the grief to part."(Li Yu, Joy at Meeting); "Wave on wave the long river eastwards rolls away; gone are heroes with its spray on spray. Success or failure, right or wrong, all turn out vain. (Yang Shen, Immortal at the River).The calligraphies of the great masters of cursive script such as Zhang $\mathrm{Xu}$, Wang His-chih and Huai $\mathrm{Su}$ also expressed the free and easy realm at the "Unity of Man and Nature " state of the Taoist philosophy. Combining with graceful fonts and abundant ink marks changes, the abstract and free expression of the vigor of strokes, tolerance and the form of the calligraphy achieved the effect described in the painting. For instance, the poetic expression of paintings was shown in the artistic effect of the works of the painters (such as Wang Wei and $\mathrm{Wu}$ Tao-Tzu) of the Pre-Tang period.

\section{THE IDEOGRAPHY OF THE PAINTING UNDER THE RESTRAINT OF THE EDUCATIONAL EVALUATION SYSTEM}

Ni Zan of the Yuan Dynasty was outstanding in expressing the humanity through landscape paintings in his pursuit of freedom and interestingness in calligraphic painting. The extreme minimalist landscape pattern with one river and two banks, which was created by $\mathrm{Ni} Z$ Zan, together with the artistic conception built by his calligraphy, had provided the literati painters of the Ming and Qing Dynasties and the following ones with a new pattern of the landscape painting. Thus the traditional Chinese painting was transformed from the realistic pattern of the Tang and Song Dynasties to the ideographic pattern after the Yuan Dynasty. After then, the imagery realm (rhythmic vitality) really became into the evaluation standard for judging the artistry of a painting, using Figure 3 as an example. The evaluation system of Chinese painting was proposed by Xie He and highly praised by Zhang Yanyuan, and then became into the mainstream gradually leading the landscape painting to be the main Chinese painting style. Its peak era reflected the highest level of the rhythmic vitality of the "six codes" in the humanistic spirit. The evaluation system of painting returned to its original point from its starting. After then, under the impact of western painting, the educational system and evaluation system of Chinese painting changed completely. Driven by the New Culture Movement, the literati disappeared and the literati painting faded away. Nevertheless, the pursuit for the painting ideas with ideographic characteristics showed its vitality regarding to the sinicization of western painting (Cao, Y., Wang, Z.X. 2010).

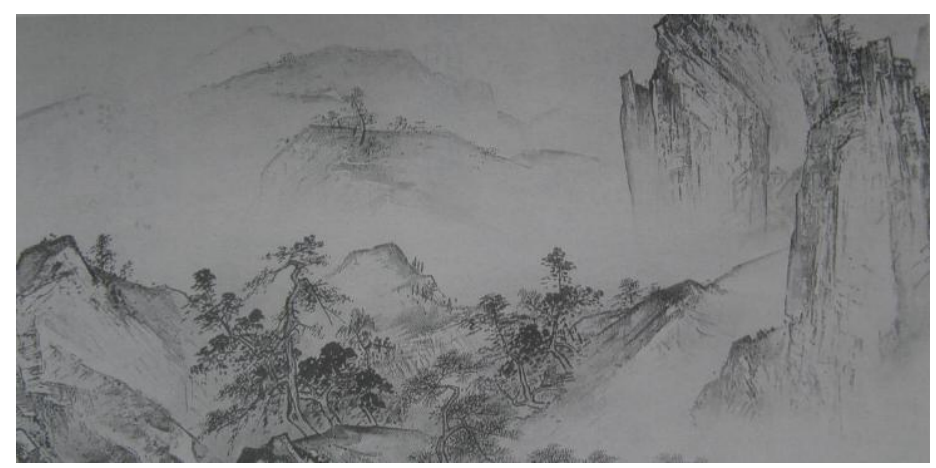

Figure 3. Xia Gui (Song) Pure Views Taipei Palace Museum

The realistic and vivid skill of the paintings that Giuseppe Castiglione presented to the Qianlong Emperor in the Qing Dynasty amazed the Emperor and the ministers and was highly praised. However, after having seen these realistic works for several times, the Emperor thought this kind of paintings, which were too realistic, were not engaging and vivid without interestingness and artistic conception. So the emperor didn't ask the Chinese painters to draw according to the style of Giuseppe Castiglione in the following paintings. The Emperor still appreciated the traditional Chinese landscape painting and regarded the rhythmic vitality of the ideography as the standard of the painting level.

Since the Republic of China, the country had faced big challenges in various aspects of the culture and revolution was the only way of national rejuvenation. The ideographic style once had difficulties in being identified and was considered as things of the ancient regime. The painting had developed blindly according to the western evaluation standard and the "rhythmic vitality" gradually became a classic term. 


\section{EXPECTATION ON THE RENASCENCE OF THE IDEOGRAPHIC CHARACTERISTICS OF THE PAINTING}

In fact, the Chinese literati (both the scholar and painter) had to find their way and explore a way for the nation under the strong western culture ever since the 1930s. The Chinese classics were kept by a few intellectuals (such as Wang Guowei and etc.) and the traditional Chinese painting headed for the folk (such as Qi Baishi and etc.). As the country was at the risk of being conquered, there was no mainstream painting style in society.

The western educational system introduced by $\mathrm{Xu}$ Beihong had vigorously driven the spread of oil painting in China but conflicted with the origin of Chinese painting when being popularized in the teaching of traditional Chinese painting, so Pan Tianshou left aside the modeling training of sketch during his teaching of traditional Chinese painting. The spirit of Chinese painting lies in the Chinese calligraphy and classics. However, the western painting occupied more than a half of the overall art space in the painting in China and just left a small space for Chinese painting to survive.

During the teaching of art class, there was once a long period that the students weren't aware that the "rhythmic vitality" was the basis of a fine painting, and the freely drawn painting was regarded as an unfinished one. There was no discussion on the painting topic of imagery spirit any more. As a result, the ideographic painting had to linger in most time of the $20^{\text {th }}$ century. Even during the period from the establishment of the PRC to the Cultural Revolution and the following decade, the complete Soviet artistic expression was also related to the western oil painting and advocated the utility function of paintings, and then became into a political tool. The personality of the painter and the common characteristics of the traditional culture were not shown any more. The concretization of artistic works dominated.

Even so, during the exploration on the painting style focusing on western oil painting, a group of Chinese painters had integrated the spirit rooted in the traditional cultural aesthetic with the imagery painting. Among these painters, there were Chinese oil painters in early of the last century such as Zhao Wou-ki who lived in Paris and Wu Guanzhong who returned after studying abroad. The reason why they could paint in the ideographic style was that they were well educated by the fine traditional culture and kept the spirit of Chinese culture. They agreed and insisted that one could only establish his own style in the circles of western painting by keeping the individuality of Chinese culture. In their works, the "ideographic characteristic" was the general feature and the "rhythmic vitality" was pursued, using Figure 4 as an example.

Nowadays, the educational system of China is still following the western system introduced by Tsai Yuean-Pei and $\mathrm{Xu}$ Beihong in the last century. In class teaching of painting and the artistic works evaluation in social activities, the ideographic characteristics was proposed again. As Chinese culture rapidly and vigorously developing along with economic prosperity, to resume the spirit of traditional Chinese painting is to restore the soul of the Chinese nation. Although there are multiple standards for the teaching and judging of the painting, the creation of oil paintings in national style, which bases on the traditional Chinese painting and uses tools and materials of oil painting, will eventually return to the expression of a natural, free and easy feeling. The ideographic characteristics will be the main style and feature of Chinese paintings.

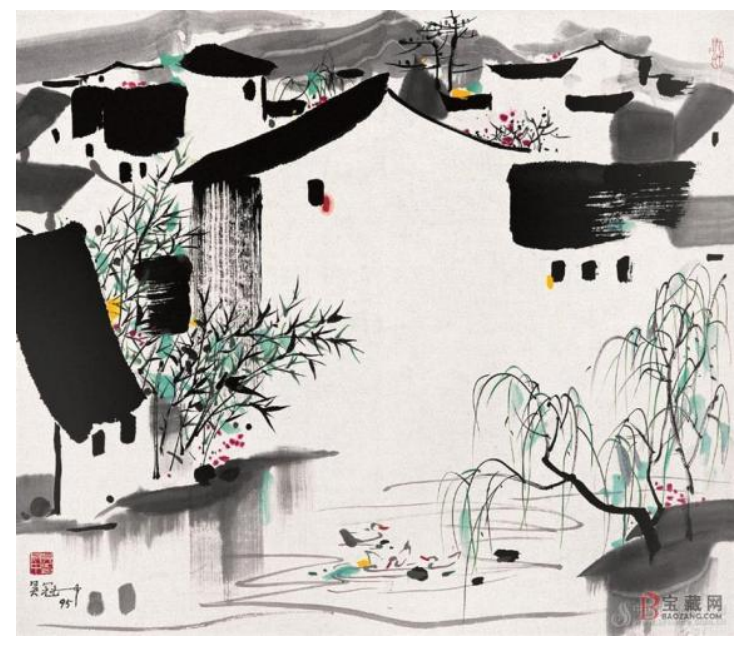

Figure 4. Wu Guanzhong (painted in 1995)

\section{REFERENCES}

[1] Sheng, J.H. 2014. Recognition of Chinese artists via windowed and entropy balanced fusion in classification of their authored ink and wash paintings (IWPs). Pattern Recognition, 47(2): 612-622.

[2] Pan, W.G., Lu, K. and Zhai R. 2013. Inscription extraction from Traditional Chinese Painting images. Proceedings of the 5th International Conference on Internet Multimedia Computing and Service (ICIMCS 2013), Hefei, 17-19 August 2013. 349-352.

[3] Cao, Y., Wang, Z.X. 2010. A survey of rendering of Chinese painting. 2010 International Conference on Multimedia Communications, Mediacom, Wuhan, 7-8 August 2010. 153-156. 